Check for updates

Cite this: RSC Adv., 2019, 9, 5978

Received 25th January 2019

Accepted 11th February 2019

DOI: $10.1039 / c 9 r a 00675 c$

rsc.li/rsc-advances

\section{The conversion of $\alpha$-pinene to cis-pinane using a nickel catalyst supported on a discarded fluid catalytic cracking catalyst with an ionic liquid layer $\dagger$}

\author{
Shunyou Hu, (D) a Linlin Wang, (DD *ab Xiaopeng Chen, ${ }^{\text {ab }}$ Xiaojie Wei, ${ }^{\text {ab }}$ \\ Zhangfa Tong (D) ab and Lijiang Yin ${ }^{a}$
}

\begin{abstract}
The concept of a solid catalyst coated with a thin ionic liquid layer (SCILL) was applied to the stereoselective hydrogenation of $\alpha$-pinene. Nickel, a non-noble metal, was supported on a discarded fluid catalytic cracking catalyst (DF3C) and then modified with different loadings of the ionic liquid 1-ethanol-3methylimidazolium tetrafluoroborate $\left(\left[\mathrm{C}_{2} \mathrm{OHmim}\right]\left[\mathrm{BF}_{4}\right]\right)$. The resulting catalysts showed a range of conversions and selectivities for the hydrogenation of $\alpha$-pinene. The SCILL catalysts afforded cis-pinane with high selectivity and their activity depended on the ionic liquid loading. For an ionic liquid loading of 10 wt\%, although the catalytic activity was suppressed, the selectivity and conversion could reach above $98 \%$ and $99 \%$, respectively. In addition, the catalyst remained stable after 13 runs and the activity was almost unchanged with the conversion maintained at approximately $99 \%$. Thus, the ionic liquid layer not only improved the selectivity for cis-pinane but also protected the active site of the catalyst and prolonged the service lifetime of the catalyst. The SCILL catalytic system provides an example of an ionic liquid catalytic system which eliminates organic solvents from the catalytic process.
\end{abstract}

\section{Introduction}

As a natural, green, and renewable product, $\alpha$-pinene has drawn great interest for applications in the pharmaceutical, bioenergy, fine chemistry, and flavouring industries. ${ }^{1}$ There are two kinds of hydrogenation products of $\alpha$-pinene, namely, cis-pinane and trans-pinane, and among these two products, cis-pinane is more desirable since the content of cis-pinane in raw materials should be greater than $90 \%$ to reduce by-products and simplify post-treatments. There is a need to design and identify more effective catalysts for the selective hydrogenation of $\alpha$-pinene to improve the yield of $c i s$-pinane. To date, various studies have focused on hydrogenation of $\alpha$-pinene, including a report by Hou et al. on $\mathrm{Ru}$ nanoparticles in aqueous micellar microreactors as catalysts with a high selectivity for cis-pinane under mild conditions. ${ }^{2}$ Milewska et al. studied biphasic hydrogenation of $\alpha$-pinene over $\mathrm{Pd} / \mathrm{C}$ under a high pressure of carbon dioxide. ${ }^{3}$ Deliy et al. reported that hydrogenation and isomerization of pinenes occur simultaneously on $\mathrm{Ru} / \mathrm{C}, \mathrm{Rh} / \mathrm{C}, \mathrm{Pt} / \mathrm{C}$,

${ }^{a}$ School of Chemistry and Chemical Engineering, Guangxi University, Nanning 530004, P. R. China. E-mail: wanglinlin1971@sina.com; Fax: +86-771-323-3718; Tel: +86-7713272702

${ }^{b}$ Guangxi Key Laboratory of Petrochemical Resource Processing and Process Intensification Technology, Nanning 530004, P. R. China

$\dagger$ Electronic supplementary information (ESI) available. See DOI: $10.1039 / \mathrm{c} 9 \mathrm{ra} 00675 \mathrm{c}$ and Ir/C catalysts. ${ }^{4}$ Selka et al. achieved excellent catalytic activity and selectivity based on their studies into hydrogenation of $\alpha$-pinene over Pd-based catalysts on different supports; however, the reusability of these catalysts was poor. ${ }^{1}$ Simakova et al. investigated the hydrogenation of $\alpha$-pinene over $4 \mathrm{wt} \%$ palladium on carbon $(\mathrm{Pd} / \mathrm{C})$ as a catalyst with $n$-octane as a solvent. ${ }^{5}$ Tanielyan et al. used ethanol as solvent in their studies of pinene hydrogenation over anchored Wilkinson catalyst. ${ }^{6}$ However, noble metal catalysts and organic solvents are expensive, environmentally unfriendly, and the lack of reusability of these catalysts poses major challenges.

Discarded fluid catalytic cracking catalyst (DF3C) is a kind of industrial waste product from petroleum refining processes. DF3C contains heavy metals such as iron, nickel, and vanadium, which were contained in the heavy oil subjected to the reactions. A large amount of DF3C is produced every year, the majority of which is sent to landfill, risking environmental pollution, from heavy metals seeping into groundwater. ${ }^{7}$ Recently, attention has been paid to recovering DF3C, and it has been applied as a catalyst for cracking of waste plastics, ${ }^{8}$ a source of heavy metals, ${ }^{7}$ and rare earth elements. ${ }^{11,12}$ DF3C is mainly composed of $\mathrm{Al}_{2} \mathrm{O}_{3}, \mathrm{SiO}_{2}$, and residual nickel, with a rich pore structure and large specific surface area; hence, DF3C might act as an effective active metal carrier.

Ionic liquid is a new molten salt system that consists of cation and anion that exist in liquid form at room temperature, 
which can be designed according to specific requirements. Ionic liquids have many properties different from conventional organic solvent, such as thermal stability, ${ }^{9}$ electrochemical stability, ${ }^{\mathbf{1 0 , 1 1}}$ and adjustable electric fields, which were the powerful supports for using ionic liquids as catalysts modifiers to achieve excellent catalytic performance and longer service lives. These features enable ionic liquid to regulate the activity and selectivity of catalysts. Owing to its unique properties, the ionic liquid is used in chemical research as a solvent for various types of reactions, ${ }^{\mathbf{1 2 - 1 6}}$ extractant in separation/purification, ${ }^{\mathbf{1 7 - 2 0}}$ and has applications in the field of electrochemistry. ${ }^{21-23}$ Zhao et al. have reported the synthesis of $\operatorname{CoS}_{x}$ nanosheets from ionic liquid and applied it for the oxygen evolution reaction. ${ }^{24}$ Zhao et al. have developed liquid-exfoliation method to produce stable and high-concentration dispersions of mono- to few-layer black phosphorus nanosheets using ionic liquid. ${ }^{25} \mathrm{Li}$ et al. has used the ionic liquid to assist synthesis of Au-Pd bimetallic particles with enhanced electrocatalytic activity. ${ }^{26}$ And Brown et al. have studied the asymmetric hydrogenation and catalyst recycling using ionic liquid and supercritical carbon dioxide. ${ }^{27}$ When an ionic liquid is used as a reaction medium, it can alter the electronic environment of catalyst active sites; thus, ionic liquids can tune the catalytic effectiveness of non-precious metal catalysts to be as good as, or even better than those of noble metal catalysts, particularly in terms of catalyst selectivity. Ionic liquids can act as selective controllers for organic transformations, such as the selective hydrogenation of nitriles or alkynes. ${ }^{28}$ The inherent high viscosity of ionic liquids causes mass transfer resistance, which severely inhibits the reaction rate. Additionally, ionic liquids are not generally massproduced but rather used on a laboratory scale, which limits the use of ionic liquids as reaction media. To address the above problems, the concept of a solid catalyst coated with a thin ionic liquid layer (SCILL) has been proposed and applied in various catalytic reactions. ${ }^{29}$ Notably, selective hydrogenation reactions show markedly enhanced selectivity compared with those of conventional solid catalysts. Schwab et al. reported a highly cisselective and lead-free hydrogenation of 2-hexyne by a supported Pd catalyst with an ionic liquid layer. ${ }^{30}$ Hou et al. reported on $\mathrm{Pd} / \mathrm{SiO}_{2}$ coated with [DMIM] $\left[\mathrm{MeHPO}_{3}\right]$ for the selective hydrogenation of acetylene. ${ }^{31}$ The excellent selectivity of SCILL-based catalysts can be mainly attributed to the filter effect, which regulates the effective concentration of substances at the active sites of catalysts together with the ligand effects of the ionic liquid, which change the electron density distribution of active sites and affect interactions of reactants and intermediates with active metals. ${ }^{32}$

In this work, a SCILL catalyst for $\alpha$-pinene hydrogenation with nickel, a non-noble metal, was developed in combination with the industrial waste carrier DF3C and the ionic liquid 1ethanol-3-methylimidazolium tetrafluoroborate ([ $\left.\mathrm{C}_{2} \mathrm{OHmim}\right]$ $\left.\left[\mathrm{BF}_{4}\right]\right)$, as shown in Scheme 1 . The effects of temperature, pressure, ionic liquid loading on the hydrogenation of $\alpha$-pinene were explored. The lifetime of the catalyst with or without ionic liquid, under the same reaction conditions was also examined. The textural and morphological properties of the catalysts were investigated through X-ray diffraction (XRD), scanning electron

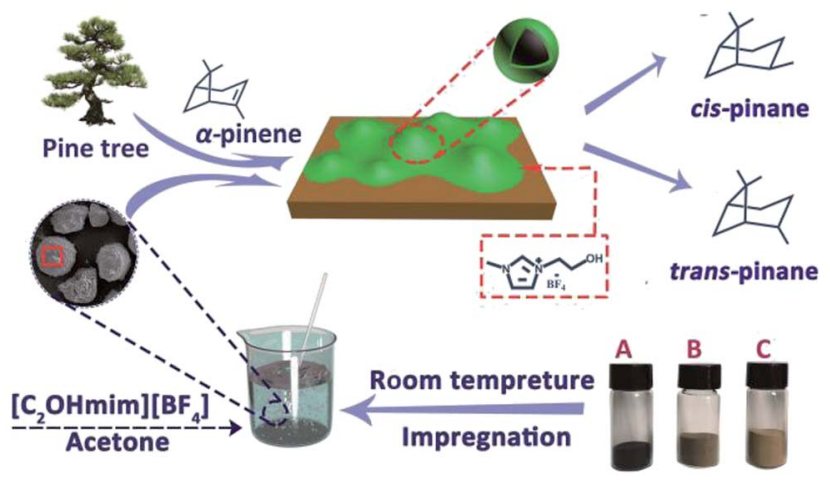

Scheme 1 The preparation procedure and application of SCILL catalyst. Ni/DF3C (A), NiO/DF3C (B), DF3C (C).

microscope (SEM) imaging, Fourier transform infrared (FT-IR), $\mathrm{N}_{2}$ adsorption-desorption, and X-ray photoelectron spectroscopy (XPS).

\section{Experimental}

\section{Materials}

Nickel(II) nitrate hexahydrate $\left(\mathrm{Ni}\left(\mathrm{NO}_{3}\right)_{2} \cdot 6 \mathrm{H}_{2} \mathrm{O}\right.$, Shanghai Xingao Chemical Reagent Co., Ltd., 99.0\%), acetone $\left(\mathrm{CH}_{3} \mathrm{COCH}_{3}\right.$, KESHI, 99.9\%), $\alpha$-pinene $\left(\mathrm{C}_{10} \mathrm{H}_{16}\right.$, Aladdin, 98\%), $N$-methylimidazole $\left(\mathrm{C}_{4} \mathrm{H}_{6} \mathrm{~N}_{2}\right.$, Aladdin, $\left.99.0 \%\right)$, 2-chloroethanol $\left(\mathrm{C}_{2} \mathrm{H}_{5} \mathrm{ClO}\right.$, Xiya Chemical Co., Ltd., 99.0\%), sodium fluoroborate $\left(\mathrm{NaBF}_{4}\right.$, Macklin, 99.0\%), and dichloromethane $\left(\mathrm{CH}_{2} \mathrm{Cl}_{2}\right.$, Beijing Chemical Works Co., Ltd., 99.0\%). DF3C was provided by Guangxi Tiandong Petrochemical Co., Ltd. All materials were commercially available and used without further purification except for the DF3C.

\section{Synthesis of ionic liquid}

The ionic liquid 1-ethanol-3-methylimidazolium tetrafluoroborate $\left[\mathrm{C}_{2} \mathrm{OHmim}\right]\left[\mathrm{BF}_{4}\right]$ was synthesized according to a literature procedure. ${ }^{33}$ First, 1-methylimidazole (50.00 g, 0.60 $\mathrm{mol})$ was placed in a round-bottom flask $(250 \mathrm{~mL})$ with a magnetic stirrer and spherical condenser. Then 2-chloroethanol ( $60.38 \mathrm{~g}, 0.75 \mathrm{~mol})$ was added slowly with a constant pressure funnel at a steady rate (two drops a second) for $72 \mathrm{~h}$ under argon atmosphere at $85{ }^{\circ} \mathrm{C}$ with oil bath heating. After two stable phases formed, the upper liquid phase (containing the reactants for the reaction) was poured off and the bottom phase was washed with ethyl acetate $(6 \times 30 \mathrm{~mL})$. The combined washings were dried by rotary evaporation over $48 \mathrm{~h}$ at $90{ }^{\circ} \mathrm{C}$ in a high vacuum environment. The dried product ( $50 \mathrm{~g}, 0.3 \mathrm{~mol})$, acetone $(150 \mathrm{~mL})$, and $\mathrm{NaBF}_{4}(38 \mathrm{~g}, 0.34 \mathrm{~mol})$ were added to a single-neck round bottom flask $(250 \mathrm{~mL})$ and stirred at room temperature for $72 \mathrm{~h}$. The liquid phase product was separated by vacuum filtration and washed with acetone $(4 \times 30 \mathrm{~mL})$ and then transferred to the vacuum rotary evaporator to remove the solvent and obtain the pure ionic liquid, $\left[\mathrm{C}_{2} \mathrm{OHmim}\right]\left[\mathrm{BF}_{4}\right]$. 


\section{Preparation of IL-Ni/DF3C}

First, DF3C was placed in a muffle furnace and calcined at a high temperature of $500{ }^{\circ} \mathrm{C}$ for $5 \mathrm{~h}$ to burn off carbon deposits on its surface. Then the DF3C was impregnated by incipient wetness with a nickel nitrate solution (10 wt\% Ni loading) and polyvinylpyrrolidone (1.5 wt\%). The mixture was left overnight at room temperature and then dried at $110{ }^{\circ} \mathrm{C}$ for $4 \mathrm{~h}$ under vacuum. The dried product was again placed in a muffle furnace and calcined at $550{ }^{\circ} \mathrm{C}$ for $4 \mathrm{~h}$ to obtain the precursor for the catalyst, NiO/DF3C. Finally, the precursor was reduced under flow of $\mathrm{H}_{2}$ under temperature programmed to obtain Ni/DF3C. The IL-Ni/DF3C was prepared by a conventional impregnation method. The acetone solution of $\left[\mathrm{C}_{2} \mathrm{OHmim}\right]\left[\mathrm{BF}_{4}\right]$ was added dropwise to the Ni/DF3C, mixed fully, and then transferred to a vacuum drying oven at $60{ }^{\circ} \mathrm{C}$ for $3 \mathrm{~h}$. The acetone slowly evaporated from the slurry; however, the ionic liquid remained on the inner surface of the Ni/DF3C as a result of its characteristically high viscosity and low volatility. The initial ionic liquid loading ranged from $0 \mathrm{wt} \%$ to $20 \mathrm{wt} \%$. The catalysts are denoted as $\mathrm{X}-\mathrm{Ni} / \mathrm{DF} 3 \mathrm{C}$, where $\mathrm{X}$ refers to the ionic liquid loading.

\section{Characterization}

XRD patterns were obtained with a Shimadzu XRD-600 advance powder diffractometer operated at $45 \mathrm{kV}$ and $40 \mathrm{~mA}$, using $\mathrm{Cu}$ $\mathrm{K} \alpha$ radiation. The samples were scanned over Bragg angles in the range from $10-80^{\circ}$ at a scan rate of $10^{\circ} \mathrm{min}^{-1}$. XPS was measured with an ESCALAB 250XI+ spectrometer, and the binding energy scales for samples were referenced by calibration to the $\mathrm{C} 1 \mathrm{~s}$ binding energy of adventitious carbon at $284.8 \mathrm{eV}$, with peaks fitted by Gaussian-Lorentzian curves with the use of XPSPEAK. SEM imaging was performed on a Zeiss Sigma HD with an SE detector. The specific surface areas, average pore width, and total pore volume were calculated with the Brunauer-Emmett-Teller (BET) equation and Barrett-Joyner-Halenda (BJH) methods with the use of a Micromeritics 3Flex instrument. FTIR measurements were performed in a Nicolet IS 10 FTIR spectrometer at a resolution of $4 \mathrm{~cm}^{-1}$ with an average of 20 background scans and 50 sample scans from 4000 to $400 \mathrm{~cm}^{-1}$.

\section{Catalyst performance testing}

Catalytic hydrogenation experiments of $\alpha$-pinene were performed in a batch reactor comprising a $100 \mathrm{~mL}$ stainless steel autoclave (Shanghai Huotong Experimental Instrument Co., Ltd., China) with a maximum pressure of $25 \mathrm{MPa}$. A schematic of the experimental setup is depicted in Scheme S1. $\dagger$ Approximately $60 \mathrm{~mL}$ of $\alpha$-pinene and $5 \mathrm{~g}$ of the catalyst were introduced into the autoclave. The air in the reactor was purged with a vacuum pump for 20 minutes. Then, hydrogen from the cylinder was introduced into the reaction still at a pressure of $5 \mathrm{MPa}$ and maintained for 20 minutes to ensure that the reactor did not leak. Then the gas in the reactor was discharged to the atmosphere through the discharge valve, and the vessel was recharged with hydrogen at $5 \mathrm{MPa}$. This operation was cycled 4 times to ensure that the reactor contained no residual air. The reactor was heated to a target temperature of $100{ }^{\circ} \mathrm{C}$ at a relatively low hydrogen pressure $(0.05 \mathrm{MPa})$ and rotation speed (50 rpm stirring rate) to avoid excessive reaction during the heating process. The stirring speed and hydrogen pressure were adjusted to the desired value (5 $\mathrm{MPa}$ ). During the reaction, the hydrogen pressure in the reactor was maintained at a constant value by controlling the inlet valve. After the reaction, cooling water was flowed through the heat exchange coil in the reaction vessel bring the temperature of the reactor to room temperature. The product was then separated from the mixture by vacuum filtration and samples were qualitatively analyzed by a gas chromatography-mass spectrometer (GC-MS) on an Agilent 6890/5973 GC-MS equipped with a HP-5MS capillary column $(30 \mathrm{~m} \times 0.25 \mathrm{~mm}$ i.d. $\times 0.25 \mu \mathrm{m}$ film thickness $)$. Quantitative analyses were carried out using GC on an HP7820 GC equipped with a flame ionization detector (FID) and an HP-5 capillary column $(30 \mathrm{~m} \times 0.25 \mathrm{~mm}$ i.d. $\times 0.25 \mu \mathrm{m}$ film thickness). The temperature of the injector and the detector were $250{ }^{\circ} \mathrm{C}$. The oven temperature was programmed as follows: from $50{ }^{\circ} \mathrm{C}$ to $65{ }^{\circ} \mathrm{C}$ at a rate of $1{ }^{\circ} \mathrm{C} \mathrm{min}^{-1}$, and finally holding at $150^{\circ} \mathrm{C}$ for $5 \mathrm{~min}$. The qualitative analysis was conducted on the basis of the holding time of the peak. The content of the reactants and products was directly obtained by the GC chemstation system, according to the area of each chromatograph peak. Conversion of $\alpha$-pinene ( $\left.X_{\alpha \text {-pinene }}\right)$ and selectivity to cis-pinane $\left(S_{\text {cis-pinane }}\right)$ were calculated by eqn (1) and (2):

$$
\begin{gathered}
X_{\alpha \text {-pinene }}=\frac{C_{\alpha \text {-pinene }, 0}-C_{\alpha \text {-pinene }}}{C_{\alpha \text {-pinene }, 0}} \times 100 \% \\
S_{c i s \text {-pinane }}=\frac{C_{c i s \text {-pinane }}}{\sum C_{\mathrm{p}}} \times 100 \%
\end{gathered}
$$

where $C_{\alpha \text {-pinane, } 0}$ is the initial concentration of $\alpha$-pinene, $C_{\mathrm{p}}$ is the concentration of the different hydrogenation products.

\section{Results and discussion}

The main goal of the present work was to achieve maximum selectivity to cis-pinane in the hydrogenation of $\alpha$-pinene. In the present work on catalyst screening for $\alpha$-pinene, Ni supported on DF3C coated with ionic liquid layer showed about 98\% selectivity to cis-pinane by suppressing the by-product formation. In continuation, detail catalyst characterization for understanding the observed highest selectivity to cis-pinane is discussed below.

Nitrogen adsorption-desorption isotherms of the catalysts were measured as shown in Table 1 . The specific surface area of the DF3C without any pretreatment was $124.06 \mathrm{~m}^{2} \mathrm{~g}^{-1}$, however, after calcination, the specific surface area of the DF3C increased to $225.74 \mathrm{~m}^{2} \mathrm{~g}^{-1}$, and the average pore width decreased from $9.23 \mathrm{~nm}$ for DF3C to $5.28 \mathrm{~nm}$ and the total pore volume increased from 0.15 to $0.16 \mathrm{~cm}^{3} \mathrm{~g}^{-1}$. These changes are likely caused by the layer of carbon on the surface of DF3C, which also contributed to catalyst deactivation. A relatively large specific surface area and specific pore volume were confirmed in the treated DF3C by SEM imaging (Fig. 1). Comparing the 
Table 1 The texture properties of the catalysts

\begin{tabular}{lccc}
\hline Samples & $\begin{array}{l}\text { Surface area } \\
\left(\mathrm{m}^{2} \mathrm{~g}^{-1}\right)\end{array}$ & $\begin{array}{l}\text { Average pore } \\
\text { size }(\mathrm{nm})\end{array}$ & $\begin{array}{l}\text { Total pore volume } \\
\left(\mathrm{cm}^{3} \mathrm{~g}^{-1}\right)\end{array}$ \\
\hline DF3C & 124.06 & 9.23 & 0.15 \\
DF3C after calcinations & 225.74 & 5.28 & 0.16 \\
Ni/DF3C & 197.83 & 6.79 & 0.16 \\
0.05-IL-Ni/DF3C & 153.72 & 9.06 & 0.15 \\
0.10-IL-Ni/DF3C & 99.38 & 10.15 & 0.14 \\
0.10-IL-Ni/DF3C (used) & 96.05 & 10.69 & 0.14 \\
0.10-IL-Ni/DF3C (20 runs) & 149.74 & 9.33 & 0.15 \\
0.15-IL-Ni/DF3C & 37.95 & 14.87 & 0.07 \\
0.20-IL-Ni/DF3C & 8.26 & 28.39 & 0.03
\end{tabular}
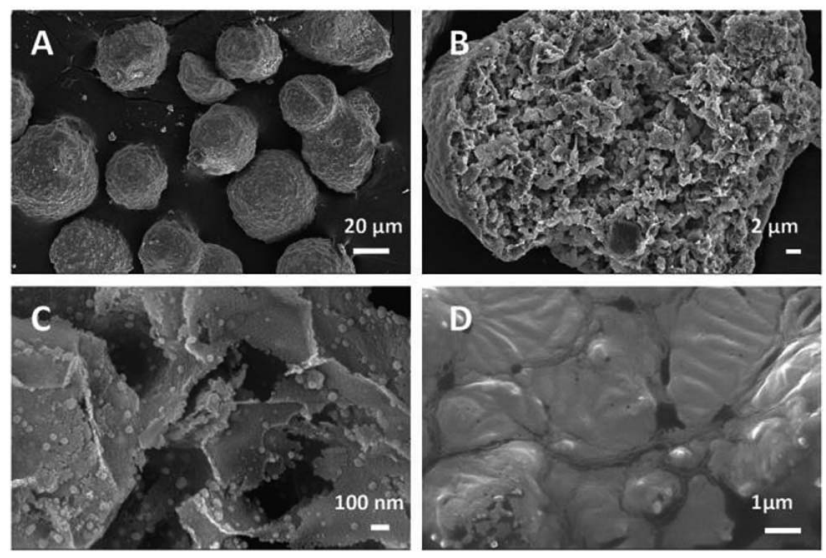

Fig. 1 SEM images of DF3C (A, B), Ni/DF3C (C), IL-Ni/DF3C (D).

catalysts with different ionic liquid loadings showed that the specific surface area of the catalyst decreased rapidly as the ionic liquid loading increased. Comparing the catalysts before and after used showed that the specific surface area of the catalysts decreased after used, which is attributed to deposition of reactants on the catalyst surface during the reaction. Furthermore, the specific surface area for 0.10-IL-Ni/DF3C after 20 runs was greater than that of $0.10-\mathrm{IL}-\mathrm{Ni} / \mathrm{DF} 3 \mathrm{C}$ (fresh), which might be caused by the leaching ionic liquid as reported by early literature. ${ }^{34}$

The morphologies and microstructures of the prepared samples were characterized by SEM. The DF3C was composed of spherical particles with a rugged surface and a particle size of approximately $50 \mu \mathrm{m}$ (Fig. 1A). Notably, the rich pore structure of DF3C and its large specific surface area (Fig. 1B), are suitable characteristics for a catalyst support. Comparing the pictures of the Ni/DF3C coated with or without ionic liquid, the ionic liquid layer caused the inner surface of the catalyst to appear smooth (Fig. 1D), unlike the rough surfaces of the DF3C support. This viscous appearance in the SEM images is attributed to the surfaces of the nickel crystal being covered by a layer of ionic liquid. SEM-EDX was used to analyze the dispersion of the ionic liquid and the active metal nickel on the DF3C (Fig. S1 †). Here, nitrogen and fluorine could be representative of the distribution of the ionic liquid, and the results showed that the ionic liquid and active metal nickel were relatively evenly distributed over the surface of the catalyst.

The X-ray diffraction (XRD) pattern of the catalysts is shown in Fig. 2. The patterns featured 13 peaks, which corresponded to zeolite $\mathrm{Y}, \mathrm{Al}_{2} \mathrm{O}_{3}$, and ZSM-5, respectively (Fig. 2a). The diffraction peaks for the DF3C sample became more intense after calcination (Fig. 2b) since the carbon covering the surface of the catalyst is burned off. For DF3C loaded nickel (Fig. 2c), in addition to the previously mentioned diffraction peaks, three characteristic peaks at $2 \theta=44.5^{\circ}, 51.8^{\circ}$, and $76.3^{\circ}$ corresponded to the (111), (200), and (220) planes of $\mathrm{Ni}$, respectively. Moreover, there was no a great difference in the diffraction patterns of Ni/DFCC coated with various contents of IL (Fig. 2cf), which indicated that the crystal structure was unaffected by the content of ionic liquid. ${ }^{35}$

The FT-IR results (Fig. S2 $\dagger$ ) showed characteristic peaks of $\left[\mathrm{C}_{2} \mathrm{OHmim}\right]\left[\mathrm{BF}_{4}\right]$ at 3557 and $3426 \mathrm{~cm}^{-1}$ resulting from telescoping vibrations of hydroxyl groups. The typical peaks for the imidazole ring were also observed at 1578, 1467, 2965, 2895, 3168 , and $3122 \mathrm{~cm}^{-1}$, which are attributed to stretching of $\mathrm{CH}_{3}(\mathrm{~N})$, stretching of the ring in plane, asymmetric stretching

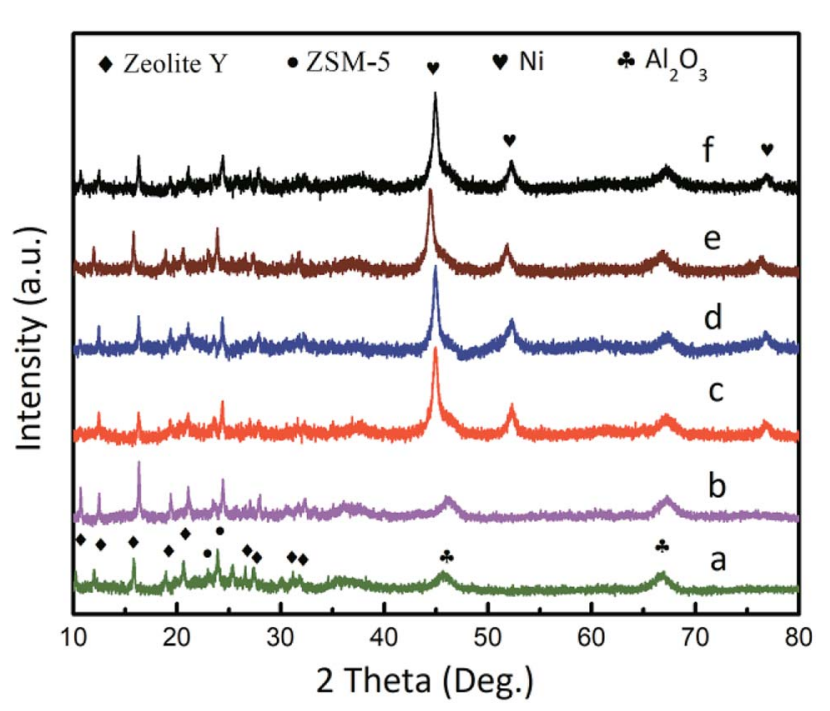

Fig. 2 XRD patterns of the DF3C (a), DF3C after calcinations (b), Ni/ DF3C (c), 0.05-IL-Ni/DF3C (d), 0.10-IL-Ni/DF3C (e), 0.15-IL-Ni/DF3C (f). 
of $\mathrm{HCH}$ on the hydroxyethyl group, symmetric stretching of $\mathrm{HCCH}$, asymmetric stretching of ring $\mathrm{HCCH}$, and stretching of $\mathrm{NC}(\mathrm{H}) \mathrm{NCH}$, respectively. In addition, a characteristic peak of $\left[\mathrm{BF}_{4}\right]^{-}$also appeared at $846 \mathrm{~cm}^{-1}$. The peaks at 3557,3426 , and $1648 \mathrm{~cm}^{-1}$ are attributed to bending and stretching vibrations of physically adsorbed water on the surface of the DF3C, whereas those at 2169,1079 , and $464 \mathrm{~cm}^{-1}$ are attributed to $\mathrm{Si}-$ $\mathrm{H}$ telescopic vibrations, $\mathrm{RO}_{4}(\mathrm{R}$ : tetrahedral $\mathrm{Si}$ or $\mathrm{Al})$ asymmetric stretching vibrations, and RO bending vibrations, respectively. There was not $\mathrm{Si}-\mathrm{O}(\mathrm{H})-\mathrm{Ni}$ peak at $985 \mathrm{~cm}^{-1}$, which indicated that no covalent bonds formed between $\mathrm{Ni}$ and DF3C.

XPS measurements (Fig. 3) were performed on the Ni/DF3C with or without ionic liquid film to better understand high stability and selectivity to cis-pinane of the Ni/DF3C coated with ionic liquid. The binding energy of the Ni $2 \mathrm{p}_{3 / 2}$ in the Ni/DF3C catalyst were $852.6 \mathrm{eV}\left(\mathrm{Ni}^{0}\right)$, and $855.6 \mathrm{eV}\left(\mathrm{Ni}^{2+}\right)$. Notably, these energies were $1.3 \mathrm{eV}$ higher than those in the IL-Ni/DF3C catalytic system. Oxidization of nickel might be attributed to reactions with oxygen in the air during the sample testing, similar to previous reports. ${ }^{36}$ The differences observed here are attributed to interactions of ionic liquid with the active metal sites. The IL may act as a ligand directly interacting with the catalytically active site. ${ }^{37}$ The lower binding energy of the SCILL catalyst suggested that $\left[\mathrm{C}_{2} \mathrm{OHmim}\right]\left[\mathrm{BF}_{4}\right]$ directly interacted with the active metal nickel, which could be related to similar effects reported in bimetallic catalysis. ${ }^{38,39}$ Supported metallic catalysts are generally highly reactive in the hydrogenation of unsaturated compounds; however, the selectivity and stability of such catalysts are generally poor. To increase the selectivity to the product of interest, conventional monometallic catalysts are typically doped with other metals or non-metal elements to regulate the electronic environment of the active components. ${ }^{32}$ For SCILL-based catalysts, a thin film of ionic liquid covers the active sites of the catalyst and interacts with the active metal by controlling the electron density at the metal sites, where the degree of electron donation correlates with the interionic interactions in the ionic liquids, which in turn controls the activity and selectivity of the catalyst. Schwab et al. used a supported Pd catalyst with an ionic liquid layer in the stereoselective hydrogenation of 2-hexyne to cis-2-hexene and achieved an outstanding yield of $88 \% .^{30}$ Babucci et al. have reported a class of atomically dispersed supported metal catalysts

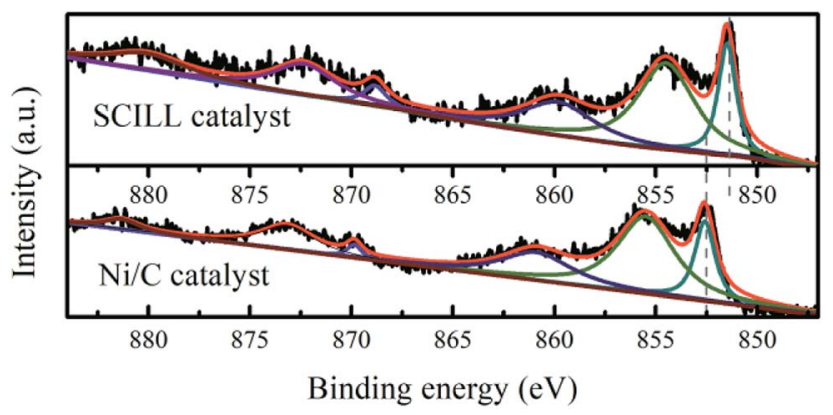

Fig. 3 XPS spectra of the $\mathrm{Ni} 2 \mathrm{p}$ region of $\mathrm{Ni} / \mathrm{DF} 3 \mathrm{C}$ and $0.10-\mathrm{IL}-\mathrm{Ni} /$ DF3C. with performance tuned by ionic liquid coatings, where the coatings controlled the electron density of active metal sites. ${ }^{\mathbf{4 0}}$

The influence of the ionic liquid loading on the activity of the catalyst in the hydrogenation of $\alpha$-pinene was examined. The conversions of $\alpha$-pinene over the catalysts with different ionic liquid loadings are shown in Fig. 4 . In the hydrogenation of $\alpha$ pinene, the Ni/DF3C system reached a total pinene conversion within $50 \mathrm{~min}$, whereas, for the SCILL system, the conversion was much lower over the same reaction time. For the $0.20-\mathrm{IL}-\mathrm{Ni}$ / DF3C catalyst, the reaction rate was very slow and the conversion of reactants was only $5.63 \%$ after $180 \mathrm{~min}$; however, for the 0.15-IL-Ni/DF3C catalysts, $38.51 \%$ conversion was achieved within the same time. Comparing the catalytic performance on SCILL and Ni/C catalyst revealed that the active metal nickel on the inner surface of the SCILL catalyst might be partially poisoned by the ionic liquid as the chemical interaction between ionic liquid and metal nickel as the results shown in XPS analysis. As Canova et $a .^{41}$ have studied that the $\alpha$-pinene hydrogenation was carried out in the presence of a hydrogenation Ni-based catalyst, wherein to obtain increased stereoselectivity, an effective amount of the reactive surface of the hydrogenation catalyst is inactivated with a catalyst modifier. Since the ionic liquid layer was only a few nm thick, when the ionic liquid loading was less enough, the diffusion inside film will play a minor role in the overall rate. ${ }^{42}$ As increasing the ionic liquid loading or even as reaction solvent, the ionic liquid might be able to block the active sites and the internal pores of the catalyst, at this time, the mass transfer resistance might not be ignored in the reaction rate. ${ }^{31}$ In summary, it can be inferred that the mass resistance alone was not the only reason for the reduced reaction rate in SCILL catalytic system, but also the chemical interaction between the $\left[\mathrm{C}_{2} \mathrm{OHmim}\right]\left[\mathrm{BF}_{4}\right]$ layer and the active site on the surface of the SCILL catalyst.

The results for selectivity as a function of $\alpha$-pinene conversion (Fig. 5) indicated that the selectivity toward cis-pinane remained constant throughout the reaction with only minor fluctuations. However, the selectivity of the catalyst varied with

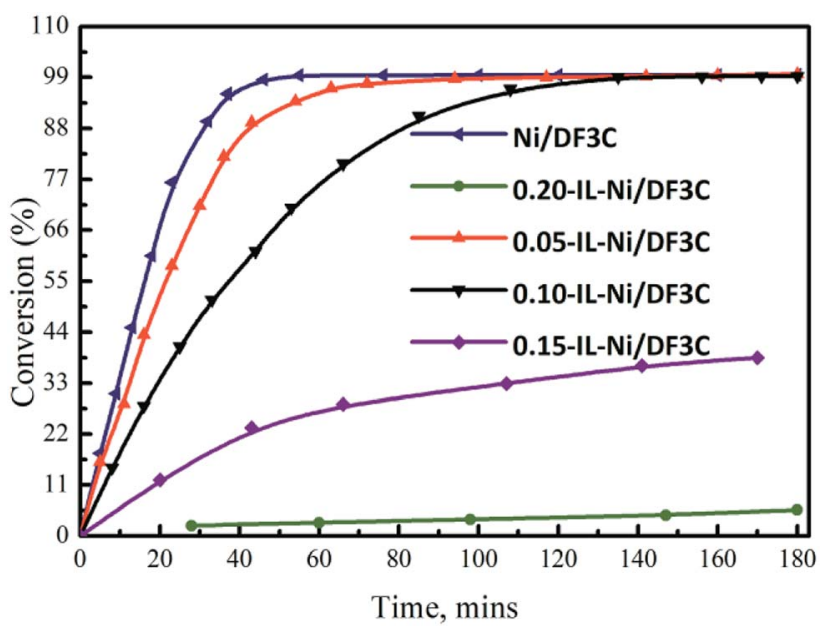

Fig. 4 Conversion vs. time profiles. Reaction conditions: $\alpha$-pinene 60 $\mathrm{mL}$, catalyst $5.0 \mathrm{~g}, \mathrm{H}_{2} 5.0 \mathrm{MPa}, 100^{\circ} \mathrm{C}, 180 \mathrm{~min}$. 


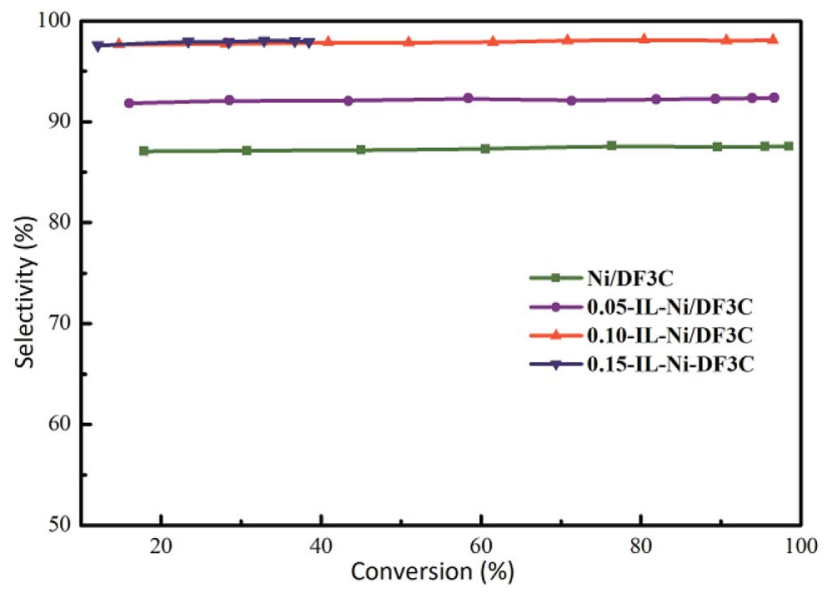

Fig. 5 Selectivity vs. conversion profiles. Reaction conditions: $\alpha$ pinene $60 \mathrm{~mL}$, catalyst $5.0 \mathrm{~g}, \mathrm{H}_{2} 5.0 \mathrm{MPa}, 100{ }^{\circ} \mathrm{C}, 180 \mathrm{~min}$.

different ionic liquid loading. When the loading of the ionic liquid was greater than $10 \mathrm{wt} \%$, the selectivity of the catalyst was more than $98 \%$; however, when the loading of ionic liquid was $5 \mathrm{wt} \%$, the selectivity decreased to approximately $90 \%$. The ionic liquid-free catalyst had a selectivity of approximately $87 \%$. The coating of $\mathrm{Ni} / \mathrm{DF} 3 \mathrm{C}$ with $\left[\mathrm{C}_{2} \mathrm{OHmim}\right]\left[\mathrm{BF}_{4}\right]$ improved the cispinene selectivity further with the activity decreased. The amount of modifier should be sufficient to effect a stereochemical improvement, and yet less than that amount which substantially adversely affects reaction rate and conversion. ${ }^{41}$ The increase in the cis-pinene selectivity after the application of the ionic liquids could be attributed to the following reasons. The active metal nickel was directly modified by the ligand effects of $\left[\mathrm{C}_{2} \mathrm{OHmim}\right]\left[\mathrm{BF}_{4}\right]$, as confirmed by XPS analysis of ILNi/DF3C (Fig. 3). Additionally, a strong electrostatic interfacial field was created by the adsorbed ionic liquid, which generated diffusion barriers and modified the access of different substances into the reaction system..$^{38}$ The bulky gem-dimethyl bridge group on the $\alpha$-pinene has a larger steric hindrance, preventing the $\alpha$-face of $\alpha$-pinene from making contact with the catalyst. ${ }^{6,43}$ Hence, hydrogen activated by nickel preferentially attacks the $\alpha$-face, which is less sterically hindered. Furthermore, the ionic liquid layer might increase the difference of the steric hindrance between $\alpha$-face and $\beta$-face, which improves the cis-pinane selectivity. ${ }^{44}$

This result is attributed to the thickness of the ionic liquid layer, which can be estimated from the mass ratio of the ionic liquid to Ni/DF3C. Interestingly, Cheng et al. have reported that less than a monolayer IL coating on the surface of the catalysts as the $m_{\mathrm{IL}} / m_{\text {catalyst }}$ ration is below 0.10 , and multilayer IL coatings when the ratio is above 0.10 , and his conclusions are a good explanation for our experimental results. ${ }^{35}$ The thickness of the ionic liquid layer was estimated by using eqn $(3)^{45}$

$$
\mathrm{ML}=\frac{m_{\mathrm{IL}} \times N_{\mathrm{A}}^{1 / 3}}{M_{\mathrm{IL}}^{1 / 3} \times m_{\text {catal }} \times S_{\mathrm{g}} \times \rho_{\mathrm{IL}}^{2 / 3}}
$$

where the film thicknesses are given in monolayers (MLs) and 1 ML of ionic is considered to be one losed layer of ion pairs vertically arranged on top of each other ${ }^{46} N_{\mathrm{A}}$ is the Avogadro constant, $S_{\mathrm{g}}$ is the specific surface area of the Ni/DF3C without ionic liquid $\left(99.75 \mathrm{~m}^{2} \mathrm{~g}^{-1}\right), \rho_{\mathrm{IL}}$ is the density of $\left[\mathrm{C}_{2} \mathrm{OHmim}\right]\left[\mathrm{BF}_{4}\right]$ $\left(1.36 \mathrm{~g} \mathrm{~cm}^{-3}, 25^{\circ} \mathrm{C}, 1 \mathrm{~atm}\right)$. The calculated MLs for the catalysts with different ionic liquid loading are listed in Table 2. As shown in Scheme S2, $\dagger$ when the ionic liquid loading was less than $10 \%$, incomplete monomolecular ionic liquid layer was formed on the catalyst surface. In this case, some of the active metal sites were not covered by the ionic liquid layer in the hydrogenation process. Thus, reactants tended to interact with the exposed active metal sites outside of the ionic liquid layer, such that the effects on the catalytic selectivity decreased, whereas the reaction rate increased. However, when the ionic loading was greater than $10 \%$ or even as reaction solvent, a multi-molecular ionic liquid layer formed on the catalyst surface and the selectivity did not increase greatly; however, the reaction rate was greatly reduced owing to an increase in the mass transfer resistance. Although, this calculation model of the ionic liquids thickness maybe brief, it could help us to understand the mechanism of the SCILL. In summary, the thickness of the ionic liquid layer plays a key role in the reaction process and the activity and selectivity of the catalyst are both related to the ionic liquid loading (i.e., the thickness of the ionic liquid layer).

To further study the effect of the catalyst coated with ionic liquid on the hydrogenation of $\alpha$-pinene, several parameters such as reaction temperature and $\mathrm{H}_{2}$ pressure were studied, and the results were shown in Fig. S3. $\dagger$ The catalytic performances of $0.10-\mathrm{IL}-\mathrm{Ni} / \mathrm{DF} 3 \mathrm{C}$ in $\alpha$-pinene hydrogenation at different temperatures under $\mathrm{H}_{2}$ pressure of $5 \mathrm{MPa}$ are shown in Fig. S3A. $\dagger$ At a lower temperature of $70{ }^{\circ} \mathrm{C}$, the conversion was low at $15.77 \%$. As the reaction temperature increased from 70 to $100{ }^{\circ} \mathrm{C}$, the conversion gradually increased and when the temperature was $100{ }^{\circ} \mathrm{C}$, the conversion reached above $99 \%$; however, the cis-pinane selectivity remained at approximately $98 \%$ with a slight decrease. It's worth noting that the ionic liquid used in our catalytic system under mild conditions (the maximum reaction temperature was $110^{\circ} \mathrm{C}$ ) was thermal stable according to a literature reported by Cao et al. ${ }^{48}$ Thus, it may be concluded that higher temperatures increased conversion but had no notable effects on catalyst selectivity, which is consistent with previous reports in the literature. ${ }^{49}$ Hydrogenation of $\alpha$ pinene was performed at different $\mathrm{H}_{2}$ pressures from 2 to $7 \mathrm{MPa}$, and the results of conversion of $\alpha$-pinene and selectivity to $c i s$-pinane are shown in Fig. S3B. $\uparrow$ The conversion increased markedly as the $\mathrm{H}_{2}$ pressure was increased and at $5 \mathrm{MPa}$ the conversion reached $99.26 \%$. In addition, the selectivity for cispinane increased slightly with increasing $\mathrm{H}_{2}$ pressure. The findings presented herein and their discussion, indicate that the reaction temperature and $\mathrm{H}_{2}$ pressure had not distinct effects on the selectivity for cis-pinane, but played an important role in the reaction rate and conversion.

Table 2 Calculated MLs for catalysts with different IL loading

\begin{tabular}{llllll}
\hline IL loading (wt\%) & 0 & 5 & 10 & 15 & 20 \\
MLs & 0 & 0.37 & 1.15 & 4.51 & 27.60
\end{tabular}


Because the ionic liquid molecule could be synthesized according to the actual needs, so far, various ionic liquids have been prepared. The conventional ionic liquid 1-butyl-3methylimidazolium tetrafluoroborate ([BMIM] $\left.\left[\mathrm{BF}_{4}\right]\right)$, 1-ethyl-3methylimidazolium tetrafluoroborate, ([EMIM] $\left.\left[\mathrm{BF}_{4}\right]\right)$, etc. have been always used as a stabilizer to protect the metal nanoparticles catalysts (NPs) from aggregating to prolong the lifetime of the NPs catalyst. Zhao et al. have synthesized welldispersed NiO nanoparticles with room temperature ionic liquid $[\mathrm{BMIM}]\left[\mathrm{BF}_{4}\right] .{ }^{50}$ One of the attractive features of ionic liquids is the option to modify them to maximize their benefits in specific reactions and a variety of functionalized ILs are now available. ${ }^{51}$ Functionalized ILs have a more unique function than traditional ionic liquid. Xue Yang et al. has studied the biphasic hydrogenation over $\mathrm{Rh}$ nanoparticles in hydroxyl functionalized ionic liquid (OH-ILs). ${ }^{51}$ For the $\alpha$-pinene hydrogenation over SCILL catalysts, we have studied the conventional ionic liquid $[\mathrm{EMIM}]\left[\mathrm{BF}_{4}\right]$ and corresponding hydroxylated ionic liquid $\left[\mathrm{C}_{2} \mathrm{OHmim}\right]\left[\mathrm{BF}_{4}\right]$ as modifier for the $\mathrm{Ni} / \mathrm{DF} 3 \mathrm{C}$ catalyst with the same thick $1 \mathrm{ML}$, the results were listed in Table S1. $\dagger$ Almost all the reactant was converted in 180 min over these three catalysts, although, maybe there were some difference in reaction rate which have been particularly discussed above. And we could found that the selectivity toward cis-pinane over [EMIM] $\left[\mathrm{BF}_{4}\right]-\mathrm{Ni} / \mathrm{DF} 3 \mathrm{C}$ was similar to that of Ni/DF3C without ionic liquid layers. However, for the $\left[\mathrm{C}_{2} \mathrm{OHmim}\right]\left[\mathrm{BF}_{4}\right]-\mathrm{Ni} / \mathrm{DF} 3 \mathrm{C}$, the selectivity toward cis-pinane increased to approximately $98 \%$, which could be attributed to some special performance of the functional ionic liquid such as viscosity, boiling point, melting point, electrochemical environment and electrochemical interaction between metal particles and ionic liquid. Ethanol has been used as solvent in general hydrogenation reaction and especially for the pinene hydrogenation. ${ }^{1}$ Cocker et al. has studied the hydrogenation of $\alpha$-pinene over $\mathrm{Pt} / \mathrm{C}$ (5 wt\%) catalyst with EtOH as solvent and obtained high selectivity for cis-pinane $(98.5 \%) .{ }^{44}$ Dorjnamjin et al. have used the OH-ILs as a reducing agent which reduces the $\mathrm{Ag}$ ion to $\mathrm{Ag}^{\mathrm{O}}$ as well as a stabilizer in forming $\mathrm{Ag}$ nanoparticles, and the $-\mathrm{CH}_{2} \mathrm{OH}$ - group in $\mathrm{OH}$-ILs is converted to the - $\mathrm{CHO}-$ group by reducing $\mathrm{Ag}$ ion and protects the $\mathrm{Ag}$ nanoparticles at the same time. ${ }^{52}$ For the SCILL catalytic system, the -OH functional group was grafted in the traditional ionic liquid [EMIM] $\left[\mathrm{BF}_{4}\right]$, making the SCILL catalytic performance was similar to the case of using $\mathrm{EtOH}$ as reaction solvent, at the same time, the lifetime of the catalyst was prolonged as a result of the OH-ILs protection. ${ }^{52}$

The work also studied varies of catalysts for the hydrogenation of $\alpha$-pinene at the same conditions as shown in Table 3. It can be seen that the hydrogenation of $\alpha$-pinene was difficult to take place without the catalyst (entry 1 ). Ni/DF3C and Pd/C showed excellent catalytic efficiency, the conversion of the $\alpha$ pinene could reach over $99 \%$, however, the selectivity toward cis-pinane was below $90 \%$. For $0.10-\mathrm{IL}-\mathrm{Ni} / \mathrm{DF} 3 \mathrm{C}$, the $\alpha$-pinene conversion and cis-pinane selectivity were over $99 \%$ and $98 \%$, respectively. Hou et al. have studied the $\alpha$-pinene hydrogenation over the $\mathrm{Ru}$ nanoparticles, and the selectivity for cis-pinane could reach above $98 \% .^{53}$ Yang et al. applied the Pd-based catalyst for the hydrogenation of the $\alpha$-pinene, and the
Table 3 Effect of catalysts on the hydrogenation of $\alpha$-pinene ${ }^{a}$

\begin{tabular}{llrl}
\hline Entry & Catalyst & $X(\%)$ & $S(\%)$ \\
\hline 1 & Blank & 1.70 & 72.36 \\
2 & Ni/DF3C & 99.47 & 87.94 \\
3 & $0.10-I L-N i / D F 3 C$ & 99.06 & 98.26 \\
$4^{b}$ & Pd/C & 99.31 & 88.91 \\
$5^{c}$ & Ru/C & 98.10 & 96.0
\end{tabular}

${ }^{a}$ Reaction conditions: $\alpha$-pinene $60 \mathrm{~mL}$, catalyst $5 \mathrm{~g}, \mathrm{H}_{2} 5.0 \mathrm{MPa}, 100{ }^{\circ} \mathrm{C}$, $180 \mathrm{~min}$. $X$ : conversion of $\alpha$-pinene; $S$ : selectivity toward cis-pinane. ${ }^{b}$ Commercial $\mathrm{Pd} / \mathrm{C}(5 \%)$, the molar ratio of the Pd to $\alpha$-pinene was similar to the case of Ni-based catalyst. ${ }^{c}$ The experimental data was obtained from ref. 47 .

conversion and selectivity could reach $99.4 \%$ and $81.3 \%$, respectively. ${ }^{49}$ In summary, metal $\mathrm{Ni}, \mathrm{Pt}, \mathrm{Ru}$-based catalysts ${ }^{47}$ could achieve high $\alpha$-pinene conversion and selectivity (over NiSCILL and Ru-based catalyst), but the price of these three kinds of metal catalysts was greatly different, metal Ni is very cheap compared with other noble metal like $\mathrm{Pt}, \mathrm{Ru}$, etc. It was possible to teach a cheap Ni-based catalyst to act like an noble Ru metal catalyst for hydrogenation reaction by coating it with an ionic liquid film. ${ }^{32}$

Finally the reusability of the catalyst coated with or without ionic liquid was also investigated for the hydrogenation of $\alpha$ pinene (Fig. 6). The recycled catalyst was easily removed from the reaction mixture by simple vacuum filtration for the next cycle. The conversion of $\alpha$-pinene was maintained at approximately $99.0 \%$ throughout the first 13 cycles for the SCILL system, indicating its excellent stability; however, in the case of the Ni/DF3C catalytic system, the conversion steadily decreased from $99.8 \%$ to $62.5 \%$ after fourth cycles. Moreover, after 13 cycles, the activity of IL-Ni/DF3C began to decrease, the conversion eventually decreased to $84.3 \%$ and the selectivity also decreased from $98.2 \%$ to $87.5 \%$. The decrease of activity and selectivity might be explained by the loss of ionic liquid from the catalyst over multiple runs owing to weak interactions between the ionic liquid and the $\mathrm{Ni} / \mathrm{DF} 3 \mathrm{C}$ as the earlier

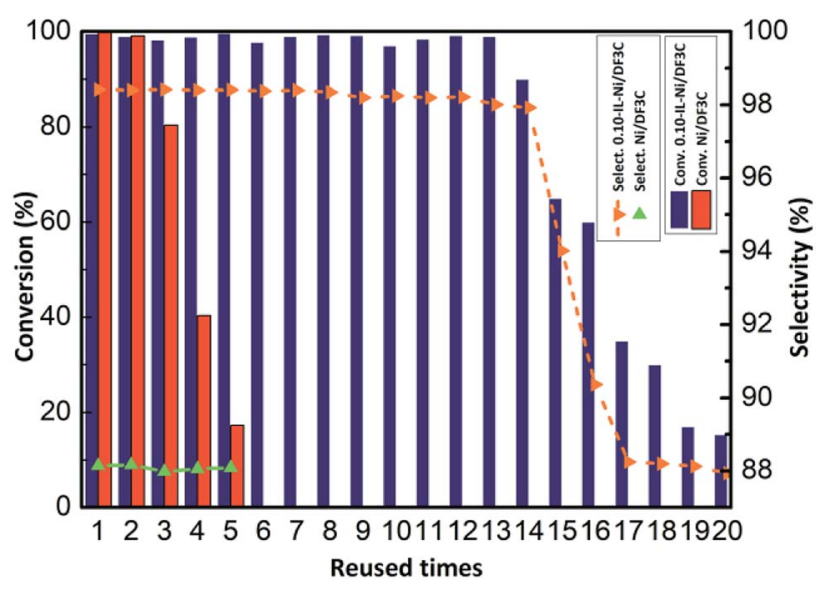

Fig. 6 Recycling of the Ni/DF3C coated with or without ionic liquid. Reaction conditions: $\alpha$-pinene $30 \mathrm{~mL}$, catalyst $2.5 \mathrm{~g}, \mathrm{H}_{2} 5 \mathrm{MPa}, 100^{\circ} \mathrm{C}$, $90 \mathrm{~min}$. 
literature reported that it should be further emphasized that even a very low solubility of the ionic liquid in the flowing liquid media will make long term stability of the SCILL catalyst system impossible due to slow but steady leaching. ${ }^{34}$ As shown in Fig. S4, $\uparrow$ The SCILL catalyst used after 20 runs has approximately $4 \%$ weight loss, which corresponds to the residual ionic liquid on the surface of the catalyst. The quality of the residual ionic liquid estimated by the thermogravimetric analysis may not be accurate enough, but it could reflect the fact of the leaching loss of ionic liquid during the multiple cycles of reaction as reported in some literature. ${ }^{34,42,54}$ Overall, these studies demonstrate greatly enhanced reusability and selectivity of the IL-Ni/DF3C catalyst, which is attributed to the effects of the ionic liquid layer.

\section{Conclusion}

In the present study, SCILL catalysts were prepared from waste industrial catalysts, solvent ionic liquid, and the non-precious metal nickel for successful application to catalysis of $\alpha$-pinene hydrogenation. To explore the mechanism of the catalyst, a series of characterization tests were performed on the catalyst. The XPS analysis confirmed that $\left[\mathrm{C}_{2} \mathrm{OHmim}\right]\left[\mathrm{BF}_{4}\right]$ donated electron density to the nickel in the catalysts, which changed the electronic properties of the active site and likely contributed to the improved selectivity to cis-pinane and greater cycling stability. In the catalyst performance tests, the ionic liquid layer also inhibited the reaction rate to some extent and improved the selectivity to cis-pinane above $98 \%$. When the loading of the ionic liquid was approximately $10 \mathrm{wt} \%$, the yield of cis-pinane improved above 97\% under the optimal catalyst and reaction conditions. Furthermore, the SCILL catalyst could be recovered easily and reused for up to 13 runs without a notable loss of the catalytic activity and selectivity. The designable molecular structure of the ionic liquid and range of immobilization modes will make it possible to design SCILL catalysts with high activity, high selectivity, and long lifetime for hydrogenation of $\alpha$-pinene and other reactions in the future.

\section{Conflicts of interest}

There are no conflicts to declare.

\section{Acknowledgements}

The authors are grateful for the financial support for this work from the National Natural Science Foundation of China (Grant No. 21878056, 31560241), Key Laboratory of Petrochemical Resource Processing and Process Intensification Technology (Grant No. 2016Z002).

\section{References}

1 A. Selka, N. A. Levesque, D. Foucher, O. Clarisse, F. Chemat and M. Touaibia, Org. Process Res. Dev., 2017, 21, 60-64.

2 S. Hou, X. Wang, C. Huang, C. Xie and S. Yu, Catal. Lett., 2016, 146, 580-586.
3 A. Milewska, A. M. B. Osuna, I. M. Fonseca and M. N. da Ponte, Green Chem., 2005, 7, 726-732.

4 I. V. Deliy and I. L. Simakova, Russ. Chem. Bull., 2008, 57, 2056-2064.

5 I. L. Simakova, Y. Solkina, I. Deliy, J. Wärnå and D. Y. Murzin, Appl. Catal., A, 2009, 356, 216-224.

6 S. Tanielyan, N. Biunno, R. Bhagat and R. Augustine, Top. Catal., 2014, 57, 1564-1569.

7 K. R. Vuyyuru, K. K. Pant, V. V. Krishnan and K. D. Nigam, Ind. Eng. Chem. Res., 2010, 49, 2014-2024.

8 F. Ferella, V. Innocenzi and F. Maggiore, Resour., Conserv. Recycl., 2016, 108, 10-20.

9 Y. Cao and T. Mu, Ind. Eng. Chem. Res., 2014, 53, 8651-8664.

10 B. Wang, L. Qin, T. Mu, Z. Xue and G. Gao, Chem. Rev., 2017, 117, 7113-7131.

11 Z. Xue, L. Qin, J. Jiang, T. Mu and G. Gao, Phys. Chem. Chem. Phys., 2018, 20, 8382-8402.

12 B. Sánchez, C. Calderón, C. Garrido, R. Contreras and P. R. Campodónico, New J. Chem., 2018, 42, 9645-9650.

13 A. A. Elgharbawy, F. A. Riyadi, M. Z. Alam and M. Moniruzzaman, J. Mol. Liq., 2018, 251, 150-166.

14 S. Tiwari, N. Khupse and A. Kumar, J. Org. Chem., 2008, 73, 9075-9083.

15 C. W. Duan, L. X. Hu and J. L. Ma, J. Mater. Chem. A, 2018, 6, 6309-6318.

16 P. Zhang, X. Tian and D. Fu, Energy, 2018, 161, 1122-1132.

17 U. Domańska, A. Wiśniewska, Z. Dąbrowski and M. Więckowski, J. Mol. Liq., 2018, 255, 504-512.

18 M. J. Jacinto, P. Djs, I. M. Marrucho, J. GonãßAlves, R. C. Willson, A. M. Azevedo and M. R. Aires-Barros, J. Chromatogr. A, 2018, 1532, 246-250.

19 Y. Zhang, X. Ji, Y. Xie and X. Lu, Appl. Energy, 2018, 217, 7587.

20 Y. Zhao, M. Pan, X. Kang, W. Tu, H. Gao and X. Zhang, Chem. Eng. Sci., 2018, 189, 43-55.

21 A. J. Lucio and S. K. Shaw, Analyst, 2018, 143, 4887-4900.

22 M. C. Buzzeo, R. G. Evans and R. G. Compton, ChemPhysChem, 2004, 5, 1106-1120.

23 H. Wan, H. Yin, L. Lin, X. Zeng and A. J. Mason, Sens. Actuators, B, 2018, 255, 638-646.

24 X. Zhao, J. Jiang, Z. Xue, C. Yan and T. Mu, Chem. Commun., 2017, 53, 9418-9421.

25 W. Zhao, Z. Xue, J. Wang, J. Jiang, X. Zhao and T. Mu, ACS Appl. Mater. Interfaces, 2015, 7, 27608-27612.

26 Z. Li, R. Li, T. Mu and Y. Luan, Chem.-Eur. J., 2013, 19, 60056013.

27 R. A. Brown, P. Pollet, E. McKoon, C. A. Eckert, C. L. Liotta and P. G. Jessop, J. Am. Chem. Soc., 2001, 123, 1254-1255.

28 H. Konnerth and M. H. G. Prechtl, Green Chem., 2017, 19, 2762-2767.

29 U. Kernchen, B. Etzold, W. Korth and A. Jess, Chem. Eng. Technol., 2007, 30, 985-994.

30 F. Schwab, N. Weidler, M. Lucas and P. Claus, Chem. Commun., 2014, 50, 10406-10408.

31 R. Hou, X. Lan and T. Wang, Catal. Today, 2015, 251, 47-52. 32 A. Jalal and A. Uzun, J. Catal., 2017, 350, 86-96. 
33 L. C. Branco, J. N. Rosa, J. J. Moura Ramos and C. A. Afonso, Chem.-Eur. J., 2002, 8, 3671-3677.

34 T. Selvam, A. Machoke and W. Schwieger, Appl. Catal., A, 2012, 445-446, 92-101.

35 Q. Cheng, S. Xu, X. Wang and C. Guo, Chem. Eng. Technol., 2013, 36, 228-232.

36 A. Jalal and A. Uzun, J. Catal., 2017, 350, 86-96.

37 M. Sobota, M. Happel, M. Amende, N. Paape, P. Wasserscheid, M. Laurin and J. Libuda, Adv. Mater., 2011, 23, 2617-2621.

38 T. Bauer, S. Mehl, O. Brummel, K. Pohako-Esko, P. Wasserscheid and J. Libuda, J. Phys. Chem. C, 2016, 120, 4453-4465.

39 Y. Zhang, Y. Qi, Z. Yin, H. Wang, B. He, X. Liang, J. Li and Z. Li, Green Chem., 2018, 20, 3944-3953.

40 M. Babucci, C.-Y. Fang, A. S. Hoffman, S. R. Bare, B. C. Gates and A. Uzun, ACS Catal., 2017, 7, 6969-6972.

41 L. A. Canova, US Pat. 4018842, 1977.

42 N. C. Antonels, M. Benjamin Williams, R. Meijboom and M. Haumann, J. Mol. Catal. A: Chem., 2016, 421, 156-160.

43 M. L. Casella, G. F. Santori, A. Moglioni, V. Vetere, J. F. Ruggera, G. M. Iglesias and O. A. Ferretti, Appl. Catal., A, 2007, 318, 1-8.
44 W. Cocker, P. V. R. Shannon and P. A. Staniland, J. Chem. Soc. C, 1966, 41-47.

45 Q. Cheng, S. Xu, X. Wang and C. Guo, Chem. Eng. Technol., 2013, 36, 228-232.

46 T. Cremer, M. Stark, A. Deyko, H. P. Steinrück and F. Maier, Langmuir, 2011, 27, 3662-3671.

47 Y. Liu, L. Li, C. Xie, S. Yu and S. Liu, Chem. Eng. J., 2016, 303, 31-36.

48 Y. Cao and T. Mu, Ind. Eng. Chem. Res., 2014, 53, 8651-8664. 49 Y. Yang, X. Liu, D. Yin, Z. Zhang, D. Lei and J. Yang, J. Ind. Eng. Chem., 2015, 26, 333-334.

50 M. Zhao, N. Li, L. Zheng, G. Li and L. Yu, J. Dispersion Sci. Technol., 2008, 29, 1103-1105.

51 X. Yang, N. Yan, Z. Fei, R. M. Crespo-Quesada, G. Laurenczy, L. Kiwi-Minsker, Y. Kou, Y. Li and P. J. Dyson, Inorg. Chem., 2008, 47, 7444-7446.

52 D. Dorjnamjin, M. Ariunaa and Y. K. Shim, Int. J. Mol. Sci., 2008, 9, 807-820.

53 S. Hou, C. Xie, H. Zhong and S. Yu, RSC Adv., 2015, 5, 8955289558.

54 T. Gallert, M. Hahn, M. Sellin, C. Schmöger, A. Stolle, B. Ondruschka, T. F. Keller and K. D. Jandt, ChemSusChem, 2011, 4, 1654-1661. 